\title{
Tobacco use among young adults in Norway, 1973-95: has the decrease levelled out?
}

Pål Kraft, Terje Svendsen

\begin{abstract}
Objective-To describe the prevalence of tobacco use among young Norwegian adults, 1973-1995.

Design-Cross sectional personal and telephone surveys.

Setting-Norway, 1973-1995.

Participants-Population based samples of Norwegians aged $16-74$ years.

Results-A trend to a decline in tobacco use among young adult Norwegians during the 1960 s and 1970 s levelled out during the $1980 \mathrm{~s}$. Hence, the total prevalence of smoking in Norway decreased by only two percentage points from 1980 to 1993 , as compared to approximately 10 percentage points in many other European countries. An increase in smoking prevalence (and in the use of snuff among males) in the age group 16-19 years has been observed in recent years. Thus smoking prevalence among young males and females in 1995 was comparable to that observed in the early 1980s.

Conclusions-Trends in tobacco use reflect an underutilisation of preventive measures in general, and health education measures in particular. Financial rem. sources appropriated for health education and information were reduced by $90 \%$ during the 1980s.
\end{abstract}

(Tobace Control 1997;6:27-32)

Keywords: tobacco use; young adults; Norway; population trend

Calculations done at the World Health Organiw sation and the University of Oxford indicate that every second smoker will die prematurely as a result of smoking. The calculations indicate that in Norway alone approximately 2000 people between the ages of 35 to 69 years die annually as a consequence of smoking, and that each of these people lose on average 21 years of life expectancy. In addition, approximately 3000 people of 70 years or older die from smoking, and each of these loses on average eight years of life expectancy. The report also provides prognoses on cancer mot tality. These prognoses indicate that among males below the age of 70 the total cancer mortality and the mortality for cancers associated with smoking are decreasing. On the other hand, among Norwegian females below the age of 70 the total cancer mortality has been increasing, which is related to an increase in the mortality of cancers associated with smoking. The mortality among this group of
Norwegian females for cancers not associated with smoking has been decreasing."

The trend in cancer mortality in Norway reffects changes in smoking behaviour which took place several decades ago. Rønneberg et $a l^{3}$ have shown that the highest proportion of smokers among males was observed in the 1950 s, while the highest proportion of smokers among females was observed around 1970. In the decades after 1955 , the proportion of daily smokers among young Norwegian males decreased, while the downward trend for female smokers started early in the $1970 \mathrm{~s}$. The proportion of daily smokers among males of between 15 and 19 years fell from $57 \%$ of the cohort borm between 1935 and 1939 to $20 \%$ of the cohort born between 1970 and 1974 , while for fernales in this age group the proportion of daily smokers fell from $36 \%$ in the cohort born 1955-59 to $25 \%$ in the cohort born in $1970-74 .^{2}$

Studies conducted on middle school pupils have shown that the proportion of smokers declined through the $1980 \mathrm{~s}^{3-5}$ Research on pupils in the seventh, eighth, and ninth grades conducted by the National Council on Smoking and Health ${ }^{5}$ has shown that in the period 1980 to 1990 the proportion of daily smokers among boys declined from $13.4 \%$ to $8.8 \%$ and among gits from $11.8 \%$ to $9.8 \%$. Klepp et al ${ }^{3}$ reported that in the period 1983 to 1989 the proportion of daily smokers among ninth graders declined from $21.8 \%$ to $15.6 \%$ among girls, while the corresponding figures anzong boys were $16.8 \%$ and $17.2 \%$.

The aim of this paper is to describe the trends in tobacco use (smoking and use of oral snuft) in Norway in the period 1973 to 1995. Because the proportion of tobacco users among young adults is a measure that is particularly sensitive to changes in factors that either encourage or discourage smoking or snuff use, we shall concentrate on trends in smoking and snuff use in this group. We shall discuss tobacco control measures used in Norway during this period.

\section{Methods}

The data presented here were collected from the annual tobacco survey of the National Council on Smoking and Health. From 1973 to 1991 these survers were carried out annually as an addendum to Statistics Norzay's annual labour market surveys. Starting in 1976 , questions concerning tobacco consumption were included in the annual fourth quarter survey. As of 1992, Statistics Norway placed the 


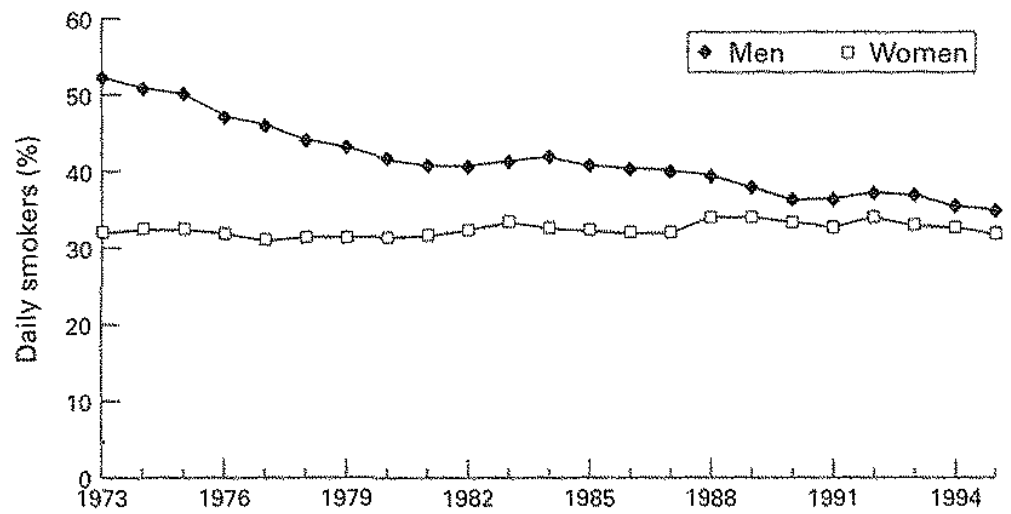

Figure $t$ Proportion of daity smokers among Norwegian males and females aged 16 to 74 years, $1973-95$

questions in the omnibus survey of the fourth quarter.

Since 1975 the samples have been designed in accordance with a standardised sampling plan-developed by Statistics Norway-and designed to ensure that the sample would be representative of the adult Norwegian popula tion. Surveys on smoking that were attached to the annual labour market surveys had a total sample of about 3000 people of ages 16 to 74 . while the total sample for the omnibus survey included about 2500 people of ages 16 to 79 (data on tobacco consumption were collected only on people of ages 16 to 74). It is important to note that when the data from one year are stratified by age, the number of respondents in each age group is rather low, For example the number of females in the age group 16-19 years is about 80 for each survey year; thus each of the data points for this age-gender sroup in fig 3 , which represent three year sliding averages, is based on a total sample of about 250 . The corresponding number of female respondents with the lowest level of education in the age group 25-35 years varies from 60 to 180 . Consequently, minor changes from one year to another should be interpreted cautiously. The description of the data thus focuses on trends occurring over many years.

As late as 1980 the data were gathered by trained interviewers conducting personal structured interviews at the respondents' homes. Between 1980 and 1991 data collection was done by telephone interviews. From 1992 Statistics Norway again turned to collecting data by personal interviews, supplemented by telephone interviews in cases where the respondent was not reached at home. This meant that in 1993 , for example, $71 \%$ of the respondents were interviewed at home, while $20 \%$ were interyiewed over the telephone. The lowest response rate occurred in the later years of the surveys. For example, there was a response rate of $71.3 \%$ in 1993 . Statistics Nor way has generated a documentation report for each survey. These reports provide detail concerning the sample size, data collection, non-response, and conditions associated with the reliability and validity of the data. (Details regarding each annual survey are available from the National Council on Tobacco and Health, Norway.)
In addition to questions concerning tobacco consumption, the surveys had questions regarding knowledge of the consequences of tobacco use, attitudes towards preventive measures, and other relevant themes. In this article we provide data concerning the following question: "Do you smoke?", with response categories of "yes, daily", "yes, occasionally", and "no" "The use of snuff was determined by the question: "Do you use snuff daily, occasionally, or never?". The question on use of snuff was included in surveys beginning in 1985. The formulation of the questions on tobacco consumption follows the recommendations of the World Health Organisation. A more detailed description of the survey form has been published elsewhere.?

The results are described in terms of three year sliding averages of the proportion using tobacco products. This means that the stated proportion of daily smokers for a given year is an average of the registered proportion of daily smokers for that year, the year before, and the year after (the result stated for 1983 is hence an average of the measures for the years 1982 , 1983, and 1984). In 1995 three data collections were undertaken. The prevalence data presented for 1995 were estimated by first computing an average of these three data collections, and then again computing the average of the prevalences from 1994 and 1995. As regards oral snuff, the most recent data are from 1994, and the data reported for 1994 thus represent an average of the data for 1993 and 1994.

\section{Results}

PROPORTION OF DAILY SMOKERS IN NORWAY, $1973-95$

Figure 1 shows the prevalence of daily smokers among Norwegian males and females of the ages 16-74 from 1973 to 1995. The proportion of daily smokers among males declined from $52 \%$ in 1973 to $36 \%$ in $1990(\mathrm{P}<0.001$, Mantel Haentzel $\chi$ test for trend for the years 1973 to 1990), after which it remained relatively stable until $1995(35 \%)(\mathrm{P}>0.05$ for the years 1991 to 1995). Among females the proportion of daily smokers was stable from $1973(32 \%)$ to $1995(32 \%)(P>0.05$ for the years 1973 to 1995$)$.

\section{DAILY SMOKERS IN NORWAY AND NM OTHER}

EUROPEAN COUNTRIES, 1980-93

Figure 2 shows the proportions of daily snokers among adults in eight European countries in 1980 and $1993^{8-10}$ In 1980 , Norway was midway among these countries, with $37 \%$ of the population being daily smokers. In 1980 The Netherlands was the worst among these countries, with $43 \%$ as daily smokers, while Finland was best at $26 \%$. In 1993 Finland was second best at $24 \%$, while. Sweden was best at $23 \%$. From 1980 to 1993, Sweden, Great Brit ain, Yreland, and The Netherlands had a reduction of about 10 percentage points, white Belgium had a decrease of 15 percentage points in the same period. In contrast, the decrease in Norway in the same period was two percentage points. As a result, Norway had the 


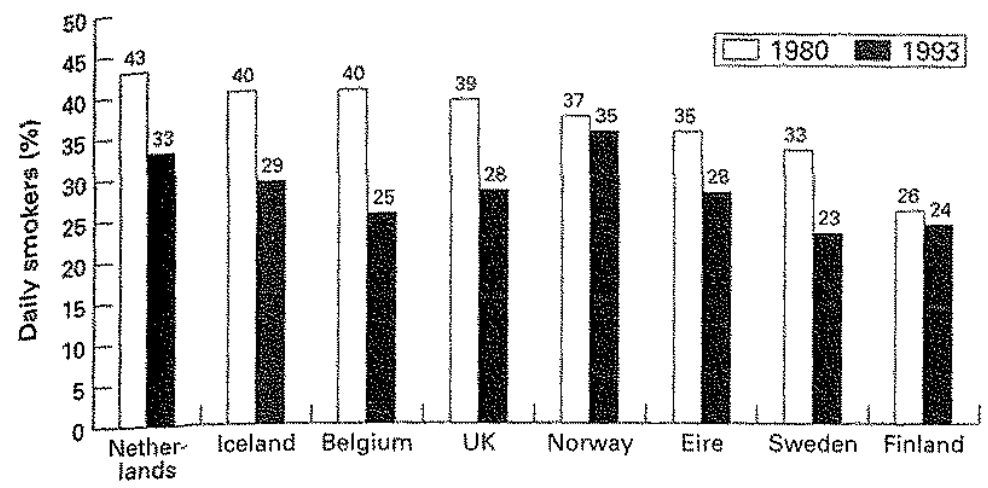

Figute 2 Proportion of daty smokers in eight European cantutes in 1980 and 1993.

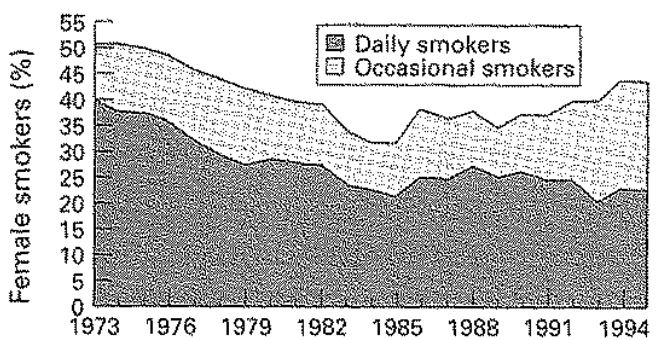

Figure 3 Proportion of smokers among Norwegian females aged 16 to 19 years, $1973-95$

highest proportion of daily smokers among these countries in 1993. (Because data on smoking prevalence in different countries may originate from surveys that are not strictly comparable, one should only make tentative conclusions when comparing them. However, data collected by a similar method over many years within a country may allow for more valid comparisons of trends between countries.)

SMOKRNG AMONG YOUNG NORWEGLAN FEMALES The proportion of females in ages $16-19$ smoking daily declined from $39 \%$ in 1973 to $21 \%$ in 1985 (fg 3). Thereafter, the proportion of daily smokers increased somewhat in this group until 1988, after which there was a slight decline again until $1995(23 \%)$. In this group of females, the proportion of occasional smokers was relatively stable at just over $10 \%$ in the period 1973 to 1990 . However, it has since increased continuously, reaching $20 \%$ in 1995 $\left(\mathbb{P}<0.01\right.$, Mantel Haentzel $x^{2}$ test for trend for the years 1990 to 1995 ). The proportion of all smokers (both daily and occasional) in this age group was $44 \%$ in 1995; one must go back to the 1970 s to observe a similarly high level.

Among females aged 20 to 24 years the proportion of daily smokers declined from $46 \%$ in 1973 to $34 \%$ in 1987, increased somewhat until $1989(37 \%)$, and then declined until $1995(30 \%)$. The proportion of occasional smokers in this group of females has varied between $10 \%$ and $16 \%$, except for the period early in the 1980 s when it approached $20 \%$. Among females aged 25 to 29 years, the proportion of daily smokers declined from $53 \%$ in 1973 to $40 \%$ in 1977 , after which it increased again to $49 \%$ in 1983 . Thereafter the proportion of daily smokers declined slightly over several years, and was $32 \%$ in 1995. The proportion of occasional smokers arnong

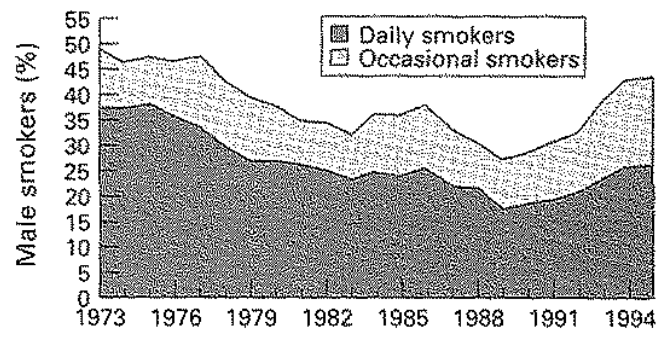

Figure 4 Proportion of smokers among Norwegian males agred 16 to 19 years, $1973-95$

females in this age group was $16 \%$ in 1973 and $15 \%$ in 1995 .

SMOKING AND SNUFF USE AMONG YOUNC YORWEGIAN MALES

In $1973,37 \%$ of males aged 16 to 19 years smoked daily (fig 4). This proportion declined to a low of $18 \%$ in 1989 . However, this proporw tion has since increased every year, to a level of $26 \%$ in 1995 , approximately the same level as in the early 1980s. From 1990 to 1995 the increase in the prevalence of daily smoking in this group of males was significant $(\mathrm{P}<0.05$, Mantel Haentzel $\chi^{2}$ test for trend for the years 1990 to 1995). During almost the entire period since 1973, the proportion of occasional smokers has remained just over $10 \%$. However, recent years have seen an increase to $18 \%$ in 1995 of occasional smokers in this group of males. The trend from 1990 to 1995 was significant $(\mathrm{P}<0.05)$.

In the age groups $20-24$ and $25-29$ years the proportions of daily smokers in 1973 were $52 \%$ and $53 \%$ respectively. For males aged of 20 to 24 years this proportion declined to $33 \%$ in 1989 , after which the decline appeats to have stopped (34\% in 1995). Among males aged 25 to 29 years a stable decline in the proportion of daily smokers can be observed for the whole period (except for a few years), reaching $37 \%$ in 1995 . The proportion of occasional smokers for both age groups has remained somewhat over $10 \%$ throughout the whole period.

For decades some of the tobacco consumed in Norway has been in the form of oral moist snuff, which is generally placed as a pinch under the upper lip. The proportion of daily and occasional snuff users among males aged 16 to 24 years increased from $9 \%$ in 1985 to $15 \%$ in 1994 ( $P<0.011$, Mantel Haentzel $x^{z}$ test for trend) (fig 5). Among males of the ages $65 \mathrm{~m}-74$ the proportion of snuff users declined from $12 \%$ in 1985 to $6 \%$ in $1994(\mathrm{P}<0.05)$.

\section{SMOKING AND LEVEL OF EDUCATTON}

Figure 6 shows the proportion of daily smokers among males and females aged 25 to 35 years according to length of formal education for the period 1976 to 1995. Among people with nine or fewer years of education, the proportion of daily smokers oscillated around $60 \%$ from 1976 to 1988. Thereafter the proportion of daily smokers among females increased to almost $80 \%$ for the years 1990 to 1991 , decining again to about $60 \%$ in 1995. Because the number of females in this group is very low, 


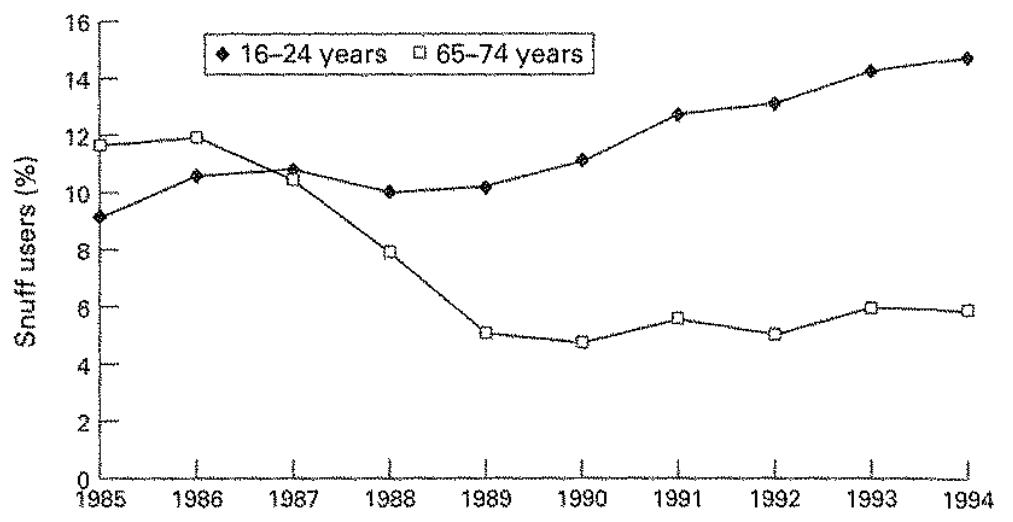

Figure 5 Proportion of daily and occasional shuff users among Norwagian males, $1985+94$.

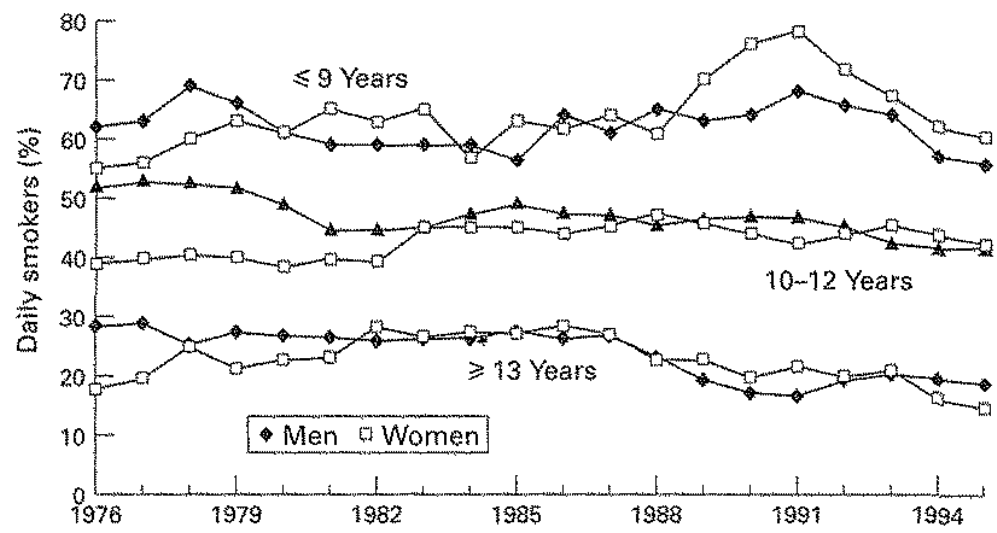

Figure 6 Proportion of Norvegian daily smokers, by education, among those aged 25 to 35 yatrs, $1976-95$.

these swings may be the resuit of random chance,

Among males (25 to 35 years) with 10-12 years of formal education, a decline from 1976 , with $52 \%$ as daily smokers, to $1980-81$ with $45 \%$ as daily smokers was observed, followed by minor swings to a level of $42 \%$ in 1995 . For fernales with this level of education, an increase in daily smokers was observed, from $39 \%$ in 1976 to $47 \%$ in 1988 . Thereafter until 1995 only minor swings occurred around a prevalence of $47 \%$.

Among females and males with education equivalent to university level (13 years of formal education), the proportions of daily smokers were $15 \%$ and $19 \%$, respectively, in 1995. Females with education at the collegiate level were at about the same smoking level as in $1976(19 \%)$, though the proportion had risen to as high as $30 \%$ through the $1980 \mathrm{~s}$. Among trales (25-35 years old) with the highest educational level, the proportion of dally smokers was just under $30 \%$ in the years 1976 to 1987 . Thereafter it declined to $17 \%$ in 1991 , and has remained stable until 1995 (19\%).

\section{Discussion}

Considering the major health policy goals, two conclusions can be drawn from these results. First, in recent decades we have come no closer to the goal of having $80 \%$ of the population smoke-free by the year 2000 , as stipulated in the Worid Health Organisation report Helse for alle for Europa." Second, sociodemographic differences in smoking behaviour are continuing, and this will probably make it more difficult to reach the goal of reducing dis parities in morbidity and mortality between different sociodemographic groups. ${ }^{\text {II }}$ It is especially critical in this context that $60 \%$ of people with no education beyond middle school are daily smokers. Although the number of people with such a low level of education is decreasing over time, the finding is grave because these people are probably exposed to an accumulation of factors related to lifestyle, living conditions, and environment (residence and work) that are unfavourable to health. ${ }^{1}$

A much larger group numerically is people of the ages 25-35 with a high school education. Thus it is especially disturbing that the propor tion of daily smokers in this group is about $40 \%$, which is twice as high as the proportion among people with university level education. In order to reach the WHO public health goal, it is necessary to invest heavily to reduce the prevalence of smoking among people with little education or with education at the high school level.

A key finding of this study is that the decline in daily smoking among young Norwegian females and males observed during the past several decades appears to have ceased toward the end of the $1980 \mathrm{~s}$. That finding-along with the significant increase in recent years in daily and occasional smoking among males of 16 to 19-is disquieting. In 1995 the total proportion of smokers (daily and occasional) among males aged 16 to 19 years was $44 \%$, which corresponds to the level found in 1977 (although the distribution of smokers between the two categories of smoking was quite differ ent). The situation among young males is also serious because snuff use has increased in the last decade. Also disturbing is the increase in occasional smoking among females aged 16 to 19 years.

However, some recent trends appear to be favourable. Among females in the age groups 20-24 and 25-29, and males of 25-29, a sligh decline in both daily and occasional smoking has occurred. Our data do not reveal the cause for this trend, but it may reflect the favourabl patterns seen in smoking prevalence among pregnant females. ${ }^{12}$ Moreover, females and males in these age groups have stated tha pregnancy and having small children at important reasons for stopping smoking. "Thi trend has occurred in parallel with medi exposure on recent research on th consequences of smoking for the fetus an small child, as well as health educatio conducted by public health authorities, wolut tary organisations, and health professionals.

WHATY DOES SMOKING PREVAYENCE TMPLY? Smoking prevalence in Norway reflects it sum total of all decisions taken by all individu als concerning smoking. The proportion smokers in a country (or a subgroup) is ther fore a characteristic of a social system-that a society. Ir reflects an aggregation of decisio and actions of individuals. The decisia making processes belind tobacco 
behaviours vary from person to person, mostly according to factors such as inheritance, personality, social environment, personal preferences, financial resources, relevant knowledge and attitudes, and so on. In psychology these factors are called proximal variables because they are "proximal" to an individual and to the decision taken. Some of these proximal variables reflect the characteristics of what are called "distal variables", which describe the qualities of the macrostructure of society. $\mathrm{Col}$ lectively these variables represent the decision structure within which an individual makes his decisions. When it is observed that smoking prevalence (a macro expression) changes over time, changes in other macro variables are usually considered as possible explanations. These kinds of changes may contribute to whether people start and stop smoking. Examples might include an increase in the average purchasing power of youth, ${ }^{13}$ emphasis on the modern ferninine image of remaining thin, ${ }^{14}$ and other trends and fads that associate smoking with the image of the modern individual.

Public health authorities have power over some factors that make up the social decision making framework which circumscribes individual decisions about smoking. These factors can be divided into three main groups: the price of tobacco (tax policy), legal measures, and health information and education of all kinds (mass media campaigns, health information in schools, and so on). The effects of these tools are well documented. ${ }^{15-17}$ When the decline in smoking appears to have stopped, this suggests that the available tools have not been fully utilised, given the trends in other macro factors encouraging smoking. However, this does not mean that implemented measures have not had any effect. The impact of these measures can only be determined by studies with a suitable design, whereas changes in smoking prevalence over time refiect a summation of all the factors infuencing smoking behaviour.

\section{THE PRECE OF TOBACCO WN NORWAY AND HN} OTHER EUTROPEAN COUNTRES

The claims that tobacco is very expensive in Norway and that tobacco products are becoming increasingly expensive are widely believed and repeated in Norwegian media. However, these claims do not conform to the facts. In 1973 and 1994 a male industrial worker with an average wage had to work 23.9 and 24.1 minutes, respectively, to buy 20 cigarettes, while the equivalent times to buy a pack of rolling tobacco were 26.1 and 30.5 minutes. The nominal price of cigarettes in Nowway appears to be high compared to other countries. ${ }^{18}$ In 1994, it cost 38 Norweglan crowns (NCR) for 20 cigarettes, which was the highest price per package in Europe. In 1994 corresponding prices were $32 \mathrm{NCR}$ in Denmark, 28 NCR in Sweden, and 27 NCR in Great Britain and Ireland. However, if purchasing power is taken into consideration, the price of cigarettes in Norway is in the middle of the European scale. Furthermore, the Norwegian nominal price for rolling tobacco is low. Calculated in terms of 20 cigarettes, the price was $19 \mathrm{NCR}$ in 1994 . In stummary, when the nominal price is adjusted to the national income level, the price of a pack of cigarettes in Norway is in the middle of the Eutopean scale, and rolling tobacco is inexpensive compared to the price of cigarettes in other European countries. ${ }^{\prime \prime}$ Moreover, Norway is unique because more than $50 \%$ of daily smokers use rolling tobacco, whereas that proportion in other Western countries is usually under $10 \%$. Among Norwegian smokers with a middle school educational level and among people residing in northein Norway, about two out of three people smoke rolling tobacco. Rolling tobacco contains two to three times more nicotine, tar, and carbon monoxide than regular cigarettes. ${ }^{20}$

Consequently, we can make four points about pricing policies. First, in Norway, it is not more expensive to buy cigarettes today than it was 20 years ago. Second, the real price for rolling tobacco in Norway is very low compared either to the price of cigarettes in Norway or to the price of cigarettes in other European countries. Third, the price of cigarettes in Norway is at about the European norm. Fourth, there may be reason to believe that the average Nowwegian smoker-and especially those with the least amount of education-are more dependent on nicotine than smokers in other countries because of the high proportion of smokers smoking rolled tobacco. One indication of this is that a survey of Norwegian smokers found that $32 \%$ of those smoking cigarettes had attempted to quit during the preceding year, while the correspond ing proportion of those rolling tobacco was $18 \%$. In sum, these factors suggest that pric ing policy has not been fully utilised in Norway during the last 20 years.

\section{USING LEGAL MEASURES}

Norway has traditionally been in the forefront of countries using legal measures to discourage smoking and to protect people against passive smoking. ${ }^{21}$ Norway was a pioneer in the banning of direct tobacco advertising (adopted in 1975) and in protecting people against passive smoking in public places and worksites (legal measures adopted in 1988). Norway still appears to be in the forefront in the use of legal measures-especially with the recent revisions that began to be implemented in 1996, and which include a minimum age of 18 years for buying tobacco, a ban on cigarette vending machines, and the prohibition of indirect advertising (to be implemented in 1997). Furm thermore, new regulations taking effect in 1996 totally prohibit indoor smoking in schools and nurseries.

\section{HEALTH TNFORMATYON AND WOUCATION}

Norway has lagged in one area: the underutilisation of health information and education to discourage tobacco consumption. Other countries have put considerably more emphasis on this than Norway during recent years. A survey in 1994 showed that compared with 10 other countries and states (including Finland, 
Canada, Great Britain, The Netherlands, and some states in the USA and Australia), Norway was in next to last place, per capita, for public spending on the prevention of tobacco use. ${ }^{22}$ For exarnple, Finland spent five times as much per inhabitant. The trend over time shows the low priority this work has been given in Norway. An average of nine million NCR were spent annually in the years 1975 to 1980 on tobacco information and education. This expenditure was reduced by $90 \%$ through the 1980 s, so that by 1994 only 0.825 million NCR were spent on these goals (including an extra appropriation for the smoke-free Olympic Games at Lillehammer). ${ }^{23}$

The low priority given to this objective is also shown by the fact that in the period 1985 to 1994, funding on the order of 300 million NCR was appropriated for information, education, and training against the spread of HIV infection ${ }^{24}$; in the same period less than 10 million NCR were appropriated for similar measures against tobacco consumption. Throughout these 10 years about 350 people in Norway have died as a result of fIrV infection, ${ }^{24}$ while the corresponding number of tobacco attributable deaths is probably about $75000 .^{25}$

\section{Conclusion}

Measured by the results achieved in preventive work against tobacco use, we conclude that in recent decades Norway has not been a pioneer. The public health goals in this area have been unrealistic, given the measures employed to achieve them. This underlines the importance of a lesson learned in other "pioneer" countries-namely, that no one can afford to rest on their laurels. ${ }^{26}$ Compared with trends in other countries and previous results in our own country, it appears that too little has been done in the category of information, education, and training. These measures, which require the largest financial resources, achieve results $\mathrm{s}^{27} 28$ and are cost-effective. ${ }^{29}$ The World Bank has shown, on the basis of American statistics, that one year of life is gained by spending $\$ 18000$ for treatment of lung cancer, $\$ 100$ to $\$ 500$ for screening for uterine cancer, and $\$ 20$ to $\$ 40$ for preventive measures against tobacco use..$^{29}$ The World Bank concludes that anti-smoking measures are among the most cost-effective health measures that can be carried out and that only vaccination programmes for small children are more cost-effective in a highly developed society. Consequently, by increasing the annual appropriation to prevent tobacco use for 1995 and 1996 to a total of 15 million NCR, Norwegian authorities can expect a high return on this investment. However, this investment still falls far short of the 55 million
NCR that the World Health Organisation recommends that Norway allocate to this work, ${ }^{23}$ especially when unfavourable trends are taken into account, which probably reflect many years of neglect.

1 Peto R, Lopez AD, Boreham J, Thun M, Heath Cj. Mortal ity from smoking in developed contries 1950-2000. Oxford: ity from smoking in developed co

2 Rønneberg A, Hafstad A, Lund KE. Røykevaner siden 1910 blant norske menn og kvinner fødr etter 1890 . Tidsskr Nor Logeforen 1994;114:1623-6.

3 Klepp KI, Wold B, Aarø LE. Røyking og bruk av alkohol blant norske skolebarn: tendenser $\mathrm{i}$ 1980-årene. Tidssk Nor Lageforen 1991;111:2859-63.

4 Irgens-Jensen $O$. Changes in the use of drugs among Norwegian youth year by year from 1968 to $1989 . \mathrm{Br}$ Addict $1991 ; 86: 1449-58$.

5 National Council on Smoking and Health. Results from the Norwegian sample studies on smoking habits amon srudents aged 13-15. Oslo: National Council on Smoking and Health, 1991.

6 World Frealth Organisation. Women and tobacco. Geneva WHO, 1992

7 National Council on Smoking and Health. Opp i royk? Om tobakksbruk $i$ Norge giennom 20 atr-1973-93. Oslo: National Council on Smoking and Health, 1994.

8 European Bureau for Action on Smoking Prevention. Tobacco and Health in the Europedn Union: an overvien. Brussels: BASP, 1994

9 Folkhäsoinstitutet. Tobaksbruket i Sverige 1983-1993. Stockholm: Tobaksprogrammet, Folkhäsoinstitutet, 1994.

10 Statistics Finland. Iobacco statistics 1993. Helsinki: Statistics Finland, 1994.

11 Ministry of Social Affairs. Utfordringer $i$ helsefremmende o forebyggende arbeid. St.meld. $\mathrm{nr} 37$ (1992-93). Oslo: Sosialforebyggende arbeid. St.

12 Erikson K, Salvesen KA , Haug K, Eik-Nes SH. Smoking habits among pregnant women in a Norwegian count 1987-1994. Acta Obstet Gynecol Scand 1996;4:355-9.

13 Oakley A, Brannen J, Dodd K. Young people, gender and smoking in the United Kingdom. Heath Prom Int 1992; $75-88$

14. Camp DE, Klesges RC, Relyea $\mathrm{G}$. The relationship betweer body weight concerns and adolescent smoking. Heal Psychol 1993;12:24-32

15 Dalla-Vorgia $P$, Sasco AJ, Skalkidis $Y$, Katsouyanni $K$ Trichopoulos D. An evaluation of the effectiveness 0 tobacco-control legislative policies in European Commu nity countries. Scand \% Soc Med 1990;18:81-9.

16 Laugesen $M$, Meads $C$. Advertising, price, income and put licity effects on weekly cigarette sales in New Zealan supermarkets. Br $\mathcal{9}$ Addict 1991;86:83-9.

17 Laugesen $M$, Meads $C$. Tobacco advertising restriction price, income and tobacco consumption in OEC countries, 1960-1986. Br ₹ Addict 1991;86:1343-54.

18 European Bureau for Action on Smoking Preventio Tobacco and Health in the European Union. An overvie Brussels: European Burean for Action on Smoki Prevention, 1994

19 Svendsen T. A comparison of prices and taxes on tobacco various European countries. Oslo: National Council Smoking and Health, 1994

20 Hauknes A. Analysis of hazardous substances in rolling tobac Oslo: National Council on Smoking and Health, 1994.

1. Roemer R. Legislative action to combat the world smoking demic, 2nd ed. Geneva: World Health Organisation, 19

22 Comite National Contre le Tabagism. Ce qu' ils dépensi pour la prévention du tabagism, quelques exemples étrang pour la prévention du tabagism, quelques exemples

23 Aare LE. Tobakksavgift og finansiering av forebyggende tith En rapport til Samarbeidsorganet for helsefremmende oppgat En rapport til Samar

24 Norges forskningsrăd. Hivlaids-forebyggende arbeid i Nor En evaluering. Oslo: Norges forskningsrąd, 1995.

En evaluering. Oslo: Norges forskningsrąd, 1995 .
25 Sanner T. Hiva koster sigarettrøykingen samfunnet? Tids Sanner T. Hiva koster sigarettroyki
Nor Leegeforen 1991;111:3420-2.

26 Rimpelä A. A critical analysis of the Finnish Tobacco Ac implementation and legitimacy, 1977-89. Tabacco Coll 1992;1:285-92

27 Flay B. Mass media and smoking cessation: a critical ren Am f Publ Health 1987;77:153-60.

28 van Reek I, Knibbe R, van Iwaarden T. Policy element predictors of smoking and drinking behaviour: the D Cohort Study of secondary schoolchildren. Health $P$ 1993;26:5-18.

29 Barnum $\mathrm{H}$. The economic burden of the global trads tobacco. Tobacto Control 1994;3:358-61. 